Asian J. Med. Biol. Res. 2021, 7 (1), 6-11; doi: 10.3329/ajmbr.v7i1.53303

\author{
Asian Journal of \\ Medical and Biological Research \\ ISSN 2411-4472 (Print) 2412-5571 (Online) \\ www.ebupress.com/journal/ajmbr
}

\title{
Article \\ Prevalence of diarrhea of goats and their concurrent blood profile in north west region of Bangladesh
}

\author{
Md. Erman Ali, Khaled Mahmud Sujan, Imrul Hasan Rasel and Md. Kamrul Islam* \\ Department of Physiology, Faculty of Veterinary Science, Bangladesh Agricultural University, Mymensingh- \\ 2202, Bangladesh \\ *Corresponding author: Professor Dr. Md. Kamrul Islam, Department of Physiology, Faculty of Veterinary \\ Science, Bangladesh Agricultural University, Mymensingh-2202, Bangladesh. Phone: +8801715414007 ; E- \\ mail: k.physiol@bau.edu.bd
}

Received: 31 January 2021/Accepted: 07 March 2021/ Published: 31 March 2021

\begin{abstract}
In Bangladesh, Diarrhea occurs in goats of any age and is responsible for poor growth in kids and a significant loss of production both through morbidity and mortality. The study was undertaken to determine the clinical prevalence of diarrheal diseases of goats with concurrent blood profile. A total of 1,007 goats were examined which were brought for treatment in the Upazilla Veterinary Hospital, Biral, Dinajpur. Among them 149 goats were found clinically affected by diarrhea and the overall prevalence of diarrheal disease in goats was $14.80 \%$. A total of 402 male and 605 female goats were examined and their diarrheal prevalence were $14.17 \%$, $15.15 \%$, respectively. The Prevalence in Jamnapari goat $(18.80 \%)$ was signicantly $(\mathrm{P}<0.01)$ higher than in Black Bengal goats $(14.26 \%)$. The prevalence $(59.52 \%)$ in suckler (below 3 months) was much significantly $(\mathrm{P}<0.001)$ higher than in young (12.47\%) and adults $(13.42 \%)$. Higher prevalence was found due to parasitic infection (38.25\%) with a declining order in PPR (30.20\%), overfeeding (24.16\%) and poisoning (7.30\%). The leukocyte number significantly $(\mathrm{P}<0.001)$ higher in goats affected by diarrhea whereas TEC, PCV, Hb and Erythrocyte Indices were in normal ranges. From this study, it can be concluded that suckler, female goats and Jamnapari goats are more susceptible to diarrhea than adult, male goats and Black Bengal goats.
\end{abstract}

Keywords: diarrhea; parasitic infection; suckler; goat

\section{Introduction}

Diarrhea in goat is a very common symptom and its seems to be one of the major community health hazards both for men and animals. It is resulted from the enteritis, characterized by abdominal pain, loose feces, increase in stool mass and defecation frequency, or stool fluidity that contain 70-95\% water (Radostits et al., 2006). There are four major causative agents of diarrhea in goats: bacteria, viruses, parasites, and management practices. Often a very black, watery diarrhea with an offensive odor is caused by coccidiosis. Diarrhea that appears very green in color and can sometimes be the consistency of a cow patty or slightly runnier is usually caused by fresh pasture. Diarrhea that is brown in color typically is a result of too much grain, worms, or stress (Radostits et al., 2000). Diarrhea can be the symptom of many different illnesses, including ruminal acidosis, copper deficiency, aflatoxin poisoning, anaphylactic shock, renal failure, selenium toxicity, coccidiosis, enterotoxemia, salmonellosis, E. coli infection and heavy parasitic infection. In addition to parasitic worms, goats and sheep may also harbor coccidian and its evidenced by diarrhea, often with flecks of blood or mucus; straining; rough hair coat; and loss of body condition (Harwood, 2006). Neonatal diarrhea in kid-goats is a common problem with not very well understood and its occurred by a variety of causes such as nutritional imbalance, faulty management and infectious agents (Zaki et al., 2010). Neonatal Diarrhea Complex usually occurs during kidding season when excessive heat or cold or heavy rains and infection can be transmitted by fecal-to-oral contact (Snodgrass et al., 1977). Infectious diarrhea affecting kids-goat occurs mainly where 
intensive systems of breeding which use paddocks, pens and indoor kids-goat sheds are employed (Aly et al., 1996). Hematological investigation in veterinary practice has become a routine part of diagnostic evaluation for food and drug safety assessment and research studies. Standardized hematological values are important complements of toxicological values evaluations of therapeutic agents (Melville et al., 1997). Hematology also valuable tools for evaluating the patho-physiology of animal both for diagnosing disease and clinical monitoring of patients (Sato et al., 2005). The establishment of base line of hematological data for animal is the basic importance for dealing with a series of practical situation including diagnosis and treatment of sick animal and experimentation (Fernie et al., 1994). However, the etiology and epidemiology of the diarrhea have been extensively studied in cattle and pigs but a very few studies have been performed to investigate the enteric pathogens that cause diarrhea in goats. Therefore, the study has been aimed with following objectives: to determine the clinical prevalence of diarrheal diseases of goats in relation to different factors like age, sex, season, breed etc. and assessment of concurrent blood profile of diarrhea affected goat.

\section{Materials and Methods}

The study was carried out at the Upazilla Veterinary Hospital, Biral, Dinajpur to determine the general clinical prevalence of diarrheal diseases in goats with the concurrent blood parameters during the six months' study period from June through November, 2014. A total of 1007 goats were examined in the Veterinary Hospital during the study period.

\subsection{General examination}

Physical condition, behavior, posture, gait, superficial skin wound, prolapse of the uterus and vagina, salivation, nasal discharge, distension of the abdomen, locomotive disturbance etc. were observed by visual examination of the patient.

\subsection{Physical examination}

Information of affected goats were recorded according to their age, sex, breed and seasons by carefully asking questions to the owner as per the strategies described by Balamurugan et al., (2012). Body condition score, temperature, consistency of feces and any prominent clinical signs were also recorded. The body surface of goat was examined for any disease. The hind quarter and thigh muscles were observed to see diarrhea, lameness, crepitation on palpation. The animals were palpated to detect any enlargement, reddening of udder or pain. In animals, mouth and feet were observed to detect any vesicle wound or salivation. Abnormal sound of respiratory tract was detected through stethoscope.

\subsection{Clinical examination}

The temperature, pulse, and respiratory rate from each of these sick animals were recorded. Clinical examinations of all goats were conducted on the basis of diseases history, owner complaint, symptoms, to diagnose the following diseases and disorders. History of each case (present and past) was carefully taken which gave a guideline for examination of the animals. According the merit of the individual case, general clinical examination was conducted on the basis of disease history and owner's complaint, symptoms and techniques such as microscopic examination, laboratory common techniques used by Samad (2001). Parasitic infestations, PPR, poison and overfeeding were diagnosed on the basis of history and clinical findings and feces examination (Radostits et al., 2000).

\subsection{Sample collection}

Blood was collected from jugular vein using disposable syringe which was treated with anticoagulant (EDTA) beforehand. After drawing of sufficient amount of blood, it was kept in sterile test tubes until use. Special care was always taken to avoid contamination as far as practicable.

\subsection{Examination of blood}

Total Erythrocyte Count (TEC), Hemoglobin Content, Hematocrit Value (PCV \%), and Total Leukocyte Count (TLC) and Erythrocyte Indices were measured according to Ghai (2007). All hematological tests were performed by Sysmex XT- 1800i Automated Hematology Analyzer in the Department of Physiology, Pharmacology and Biochemistry, Haji Mohammad Danesh Science and Technology University, Dinajpur within two hours of collection. 


\subsection{Data analysis}

All the data that were collected (age, sex, breeds, disease and seasonality) were entered to MS excel (Microsoft office 2007, USA) and analyzed by using SPSS version 13 (Coakes et al., 2006). Descriptive statistics were used to determine the prevalence of the disease and the chi- square $\left(\chi^{2}\right)$ test was utilized to examine the significance of the differences observed within the categories analyzed.

\section{Results}

\subsection{Overall prevalence of diarrheal disease in goat}

Throughout the whole study period, a total of 1007 goats were examined and among them 149 goats were clinically affected by diarrhea, so the overall prevalence of diarrheal disease in goat was $14.80 \%$. Table 1 shows that out of total 402 male goats, 57 were clinically affected by diarrhea and the prevalence of diarrheal disease in these goats was $14.17 \%$. A total of 605 female goats were examined, among them 92 females were clinically affected by diarrhea and the prevalence in female goat was $15.15 \%$. From the table 1 , it was found that a total of 42 suckler (0-3months) were examined, among them 25 sukler goat were clinically affected by the diarrhea and the prevalence of diarrheal disease in suckler goats was 59.52\%. On the other hand, a total of 585 young (above 3 month-12 month) goats were examined, among them 73 goats were clinically affected by diarrhea and the prevalence of diarrheal disease in young goats was $12.47 \%$ and a total of 380 adult (above 12 months) goats were examined, among them 51 adult goats were clinically affected by diarrhea and the prevalence of diarrheal disease in adult goats was $13.42 \%$. Table 1 also shows a total of 890 Black Bengal goats were examined, among them 127 Black Bangel goats were clinically affected by diarrhea and the prevalence of diarrheal disease in Black Bengal goats was $14.26 \%$. On the other hand, 117 Jamnapari goats were examined, among them 22 Jamnapari goats were clinically affected by diarrhea and the prevalence of diarrheal disease in Jamnapari goats was $18.18 \%$. A total of 149 goats were affected by diarrhea through parasitic, over feeding, PPR, poisons were $57,36,45,11$ and prevalence were $38.25 \%, 24.16 \%, 30.20 \%, 7.30 \%$, respectively.

\subsection{Season linked prevalence}

Table 2 shows the seasonal impact on diarrheal disease outbreak in goat. The goats were examined during the month of June, July, August, September, October, November and their number were 150, 200, 130, 142, 185, 200 , respectively and clinically affected by diarrhea $18,23,19,25,30,34$ and their prevalence was $12.0 \%$, $11.5 \%, 14.61 \%, 17.60 \%, 16.21 \%, 17.0 \%$, respectively.

\subsection{Blood profile of controlled and diarrheal goat}

The blood profile of two group (controlled and diarrhea affected) of goat are presented in the table 3. TEC, TLC, Hb, PCV, MCV, MCH, MCHC value of diarrheic goats were $15.46 \pm 1.28\left(\mathrm{million} / \mathrm{mm}^{3)}, 22.14 \pm 5.77\right.$ (thousand $\left./ \mathrm{mm}^{3}\right), 8.82 \pm 0.75(\mathrm{gm} \%), 25.32 \pm 2.13(\%), 15.80 \pm 1.35\left(\mu \mathrm{m}^{3}\right), 5.52 \pm 0.46(\mathrm{pg})$ and $33.20 \pm 0.50(\mathrm{gm} \%)$, respectively.

Table 1. Effect of breed, age, sex and diseases on the prevalence of diarrhea in goat.

\begin{tabular}{|c|c|c|c|c|}
\hline Factors & Parameter & $\begin{array}{l}\text { Animal } \\
\text { Examined }\end{array}$ & $\begin{array}{l}\text { Clinically diarrhea } \\
\text { affected }\end{array}$ & Prevalence (\%) \\
\hline \multirow[t]{2}{*}{ Breed } & Black Bengal & 890 & 127 & 14.26 \\
\hline & Jamnapari & 117 & 22 & $18.80 *$ \\
\hline \multirow[t]{3}{*}{ Age } & Suckler(0-3months) & 42 & 25 & $59.52 * *$ \\
\hline & Young (above 3-12months) & 585 & 73 & 12.47 \\
\hline & Adult(above 12 months) & 380 & 51 & 13.42 \\
\hline \multirow[t]{2}{*}{ Sex } & Male & 402 & 57 & 14.17 \\
\hline & Female & 605 & 92 & 15.15 \\
\hline \multirow[t]{4}{*}{ Diseases } & Parasitic & \multirow[t]{4}{*}{149} & 57 & 38.25 \\
\hline & Over feeding & & 36 & 24.16 \\
\hline & PPR & & 45 & $30.20 *$ \\
\hline & Poisoning & & 11 & 7.30 \\
\hline
\end{tabular}

\footnotetext{
$*=$ significant 1 percent $(\mathrm{P}<0.01) * *=$ highly significant 0.01 percent $(\mathrm{P}<0.001)$
} 
Table 2. Effect of season on the prevalence of diarrhea in goat.

\begin{tabular}{|l|l|l|l|}
\hline Month & Animal Examined & Clinically diarrheal affected & Prevalence (\%) \\
\hline June & 150 & 18 & 12 \\
\hline July & 200 & 23 & 11.5 \\
\hline August & 130 & 19 & 14.61 \\
\hline September & 142 & 25 & 17.60 \\
\hline October & 185 & 30 & 16.21 \\
\hline November & 200 & 34 & 17.0 \\
\hline
\end{tabular}

Table 3. Hematological parameters of controlled and diarrheal goat.

\begin{tabular}{|l|l|l|}
\hline Parameter & Controlled/healthy & Diarrheal affected \\
\hline $\mathrm{RBC}\left(10^{6} / \mu \mathrm{L}\right)$ & $15.68 \pm 1.90$ & $15.46 \pm 1.28$ \\
\hline $\mathrm{WBC}\left(10^{3} / \mathrm{mL}\right)$ & $12.72 \pm 1.99$ & $22.14 \pm 5.77^{*}$ \\
\hline $\mathrm{Hb}(\mathrm{g} \%)$ & $8.90 \pm 0.70$ & $8.82 \pm 0.75$ \\
\hline $\mathrm{PCV}(\%)$ & $26.80 \pm 4.32$ & $25.32 \pm 2.13$ \\
\hline $\mathrm{MCV}\left(\mu \mathrm{m}^{3}\right)$ & $16.26 \pm 1.16$ & $15.80 \pm 1.35$ \\
\hline $\mathrm{MCH}(\mathrm{pg})$ & $5.60 \pm 0.46$ & $5.52 \pm 0.46$ \\
\hline $\mathrm{MCHC}(\mathrm{g} \%)$ & $34.78 \pm 0.79$ & $33.20 \pm 0.50$ \\
\hline
\end{tabular}

$*=$ significant 1 percent $(\mathrm{P}<0.01) * *=$ highly significant 0.01 percent $(\mathrm{P}<0.001)$

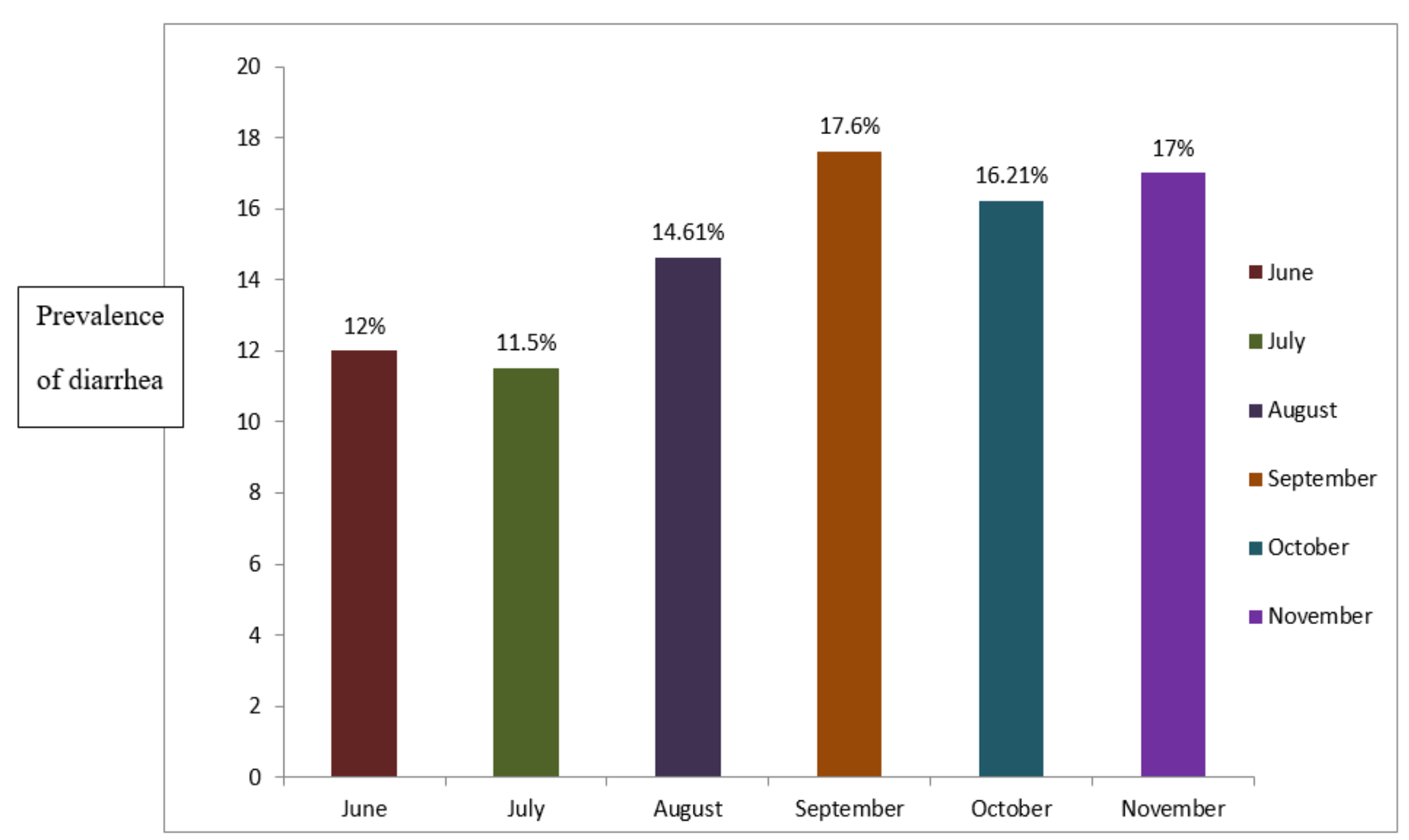

Figure 1. Seasonal effect on the prevalence of diarrhea in goats.

\section{Discussion}

The overall prevalence of diarrheal disease in goat is $14.80 \%$ and the results earlier supported by Nath et al., (2014) but Mahmood et al., (2014) who revealed an overall prevalence of diarrhea in goats to be 36.7\%. Table 1 shows that the prevalence of diarrheal disease in male goats was $14.17 \%$ and the prevalence in female goats was $15.15 \%$. Female goats were more susceptible than the male. The present study further supports the observation of Greenwood et al., (1995) who found 58\% of female goats were infected with infectious diseases. So the prevalence of diarrheal disease is slightly higher in female than in male goats. The study revealed no statistically significant difference among the sex which is contrary with the findings of Rahman et al., (2004). From the 
table-1 it was found that the prevalence of diarrheal disease in suckler goats was $59.52 \%$ which was highly significant $(\mathrm{P}<0.001)$ on the other hand, the prevalence of diarrheal disease in young goats were $12.47 \%$, the prevalence of diarrheal disease in adult was $13.42 \%$. So we may say that the prevalence of diarrheal disease was much higher suckler goat (59.52\%) compared to young (12.47\%) and adult (13.42\%). These observations support the earlier reports of Hossain et al., (1992) who reported 58.2\% mortality of kids due to diarrhea through gastro- intestinal (GI) helminthiasis and Samad (2001) reported 82.62\% clinically sick kids had GI parasitic infection. Table 1 also shows the effect of breed on the prevalence of diarrhea in goats. The prevalence of diarrheal disease in Black Bengal goat was $14.26 \%$. On the other hand, the prevalence of diarrheal disease in Jamnapari goat was $18.18 \%$ which was statistically significant $(\mathrm{P}<0.01)$. The prevalence of diarrheal disease was slightly higher in Jamnapari goats (18.80\%) than in the Black Bengal goats (14.26\%). Higher incidence in Black Bengal goats may be due to immunosuppression and irregular vaccination compared to Jumnapari (Mondal et al., 1995). It was found that the prevalence of various infectious diseases was highest in Black Bengal goats than in other goat breeds. Breed susceptibility of various infectious diseases of this study is supported by the findings of Dey et al., (2007); Kashem et al., (2011). Table-1 also revealed that a total of 149 goats were affected by diarrhea through parasitic, over feeding, PPR and poisoning, and their prevalence were $38.25 \%, 24.16 \%, 30.20 \%, 7.30 \%$, respectively. It has been evident that the diarrhea caused by PPR infection revealed the highest prevalence which was in close agreement with the earlier report made by Singh et al., (2004). Table 2 shows the seasonal impact on diarrheal disease outbreak in goat. The goat was examined during the month of June, July, August, September, October, November and the prevalence of diarrheal disease in goats were $12.0 \%, 11.5 \%, 14.61 \%, 17.60 \%, 16.21 \%, 17.0 \%$, respectively. The prevalence of diarrheal disease in goat is higher in the month of September and lower in the month of July. But the table-2 shows that the prevalence of diarrhea is increasing gradually from the hot season to the winter season. The exact cause behind this pattern of prevalence depending on season is not that much clear but it may be due to cold weather, which is the predispose of diarrhea and the report was similar to the report made by Mahmood et al., (2014). Table-3 shows that, the blood profile - TEC, TLC, Hb, PCV, MCV, MCH, MCHC of diarrheic goats were $15.46 \pm 1.28$ (million $/ \mathrm{mm}^{3}$ ), 22.14 \pm 5.77 (thousand $/ \mathrm{mm}^{3}$ ), $8.82 \pm 0.75(\mathrm{gm} \%), 25.32 \pm 2.13(\%), 15.80 \pm 1.35\left(\mu \mathrm{m}^{3}\right), 5.52 \pm 0.46$ (pg) and $33.20 \pm 0.50(\mathrm{gm} \%)$ respectively. the mean of TEC, Hb, PCV, MCV, MCH and MCHC were almost similar (slightly reduced) and do not differ significantly among the values. The exact cause of reduction in TEC, $\mathrm{Hb}$ and $\mathrm{PCV}, \mathrm{MCV}, \mathrm{MCH}$ and $\mathrm{MCHC}$ might be due to gastrointestinal inability to synthesize adequate amount of vitamin B12 and some other unknown erythropoietic factors (Pond et al., 1995). It is known that ruminant stomach specially the rumen microbes synthesize vitamin $\mathrm{B}_{12}$ by using cobalt from the diet. This vitamin B12 activates folic acid for the erythropoiesis. On the other hand, the WBC level in diarrheic goat differs significantly $(\mathrm{P}<0.001) 12.72 \pm 1.99$ to $22.14 \pm 5.77$. The result was earlier supported by the result of Zaki et al., (2010). The exact cause is still unknown but this elevated number of WBC might be due to infection through bacteria, virus, parasite, protozoa etc. (Ghai, 2007).

\section{Conclusions}

A large number of goat populations are decreasing every year due to diarrhea. The present study suggest that diarrhea is more prevalent in suckler, female goats, Jamnapari goats, winter season and parasitic infection than adult, male goats, Black Bengal goats, summer season and other diseases. Leukocyte count is increased in diarrheic goats whereas other hematological parameters become unchanged. Further study is needed to know the actual cause of the diarrhea and correlate changes in the blood profile of the diarrheic goats.

\section{Acknowledgements}

The authors thank the authority of Department of Physiology, Pharmacology and Biochemistry, Haji Mohammad Danesh Science and Technology University, Dinajpur for performing the Total Erythrocyte Count (TEC), Hemoglobin Content, Hematocrit Value (PCV \%), Total Leukocyte Count (TLC) and Erythrocyte Indices respectively.

\section{Conflict of interest}

None to declare.

\section{References}

Aly AO, HA Zamzam, KH Kohilo and AR El-Sheilch, 1996. Some studies on clinical, hematological and biochemical changes in diarrheic neonatal buffaloe-calves with reference to hygienic condition. Assiut Vet. Med. J., 35: 91-101. 
Balamurugan V, P Saravanan, A Sen, KK Rajak and RK Singh, 2012. Prevalence of peste des petites ruminants among sheep and goats in India. J. of Vet. Sci., 13: 279-285.

Coakes SJ, L Steed and P Dzidic, 2006. SPSS Version 13.0 for Windos. John Willey and Sons Australia Ltd., Australia.

Dey BK, MS Ahmed and MU Ahmed, 2007. Rotaviral diarrhoea in kids of Black Bengal goats in Mymensingh. Ban. J.Vet.Med., 5: 59-62.

Fernie S, E wrenshall, S Malcolm, F Bryce and DL Arnold, 1994. Normative hematologic and serum biochemical value for adult and infant rhesus monkey (Macaca mulatta) in a controlled Labrotory Environment. J. Toxi., 42: 53-72.

Ghai CL, 2007. A Textbook of Practical Physiology. Jaypee Brothers Medical Publishers (p) Ltd: New Delhi, India.

Greenwood PL, RN North and PD Kirkland, 1995. Prevalence spread and control of caprine arthritisencephalitis virus in dairy goat herds in New South Wales. Austral. Vet. Sci. J., 72: 341-5.

Harwood D, 2006. Goat health and welfare: a veterinary guide. Marlborough, Crowood Press.

Hossain MI, MM Hossain, BMA Hannen and AC Wadud, 1992. A note on mortality in young calves due to gastro-intestinal helminthiasis in and around BAU Campus,” Bang. J. Anim. Sci., 21:127-129.

Kashem MA, MA Hossin, SSU Ahmed and MA Halim, 2011. Prevalence of diseases, morabidity and mortality of Black Bengal Goats under different management systems in Bangladesh. Univ. J. Zool. Rajshahi Univ., 30: 1-4.

Mahmood AK, MS Khan, MA Khan and M Bilal, 2014. Prevalence of salmonella in diarrheic adult goats in field conditions. J. of Ani. \& Pla. Sci., 24: 98-102.

Melville GS, JR Whitecomb and RS Martinez, 1997. Hematology of Macaca mullata monkey. Lab. Ani. Care., 17: 189-198.

Mondal AK, AP Chottopadhuay, SD Sarkar, GR Saha and MK Bhowmik, 1995. Report on epizootological and clinic-pathological observation on Pest des Petits Ruminant (PPR) in west Bengal. Ind. J. of Anim. Health., 64: 261.

Nath TC, MJU Bhuiyan, MA Mamun, R Datta, SK Chowdhury, M Hossain and MS Alam, 2014. Common infectious diseases of goats in Chittagong district of Bangladesh. Int. J. of Scienti. Res. Agri. Sci., 1: 43-49.

Pond WG, DC Church and KR Pond, 1995. Basic Animal Nutrition and Feeding. $4^{\text {th }}$ Edition. John Wily and Sons. New York.

Radostits OM, DC Blood and CC Gay, 2006. Veterinary Medicine. A Textbook of Disease of Cattle, Sheep, Pigs, Goats and Horses. $10^{\text {th }}$ Edn. Philadelphia, Sydney, Tokyo, Toronto.

Radostits OM, CV Gay, DC Blood and KM Hinchcliff, 2000. Veterinary Medicine. $9^{\text {th }}$ Edn., WB Saunders, London.

Rahman AU, M Ashfaque, SU Rahman, M Akhtar and S Ullah, 2004. Pest des petits ruminants antigen in mesenteric lymph nodes of goats slaughtered at D.I. Khan. Pak. Vet. J., 2: 159-160.

Samad MA, 2001. Poshu Palon O Chikitsavidya, $2^{\text {nd }}$ edn., LEP Pub. No. 08, BAU Campus, Mymensingh, Bangladesh.

Sato A, LA Fairbanks, T Lawson and GW Lawson, 2005. Effect of age and sex on hematologic and serumbiochemical values of vervet monkeys (Chlorocebus aethiops sabaeses) Contemp. Tropi. Lab. Ani. Sci., 44:29-34.

Singh RP, P Saravanan, B Sreenivasa, RK Singh and SK Bandyopadhyay, 2004. Prevalence and distribution of Peste des Petits Ruminants' virus infection in small ruminants in India. Rev. Sci. and Tech., 23: 807-819.

Snodgrass DR, JA Herring, KA Linklater and DA Dyson, 1977. A survey of rotaviruses in sheep in Scotland. Vet. Rec., 100: 344.

Zaki MS, NS Ata, SI Shalaby and EM Zytoon, 2010. Diarrhoea in neonatal baraki kids-goats. Life Sci. J., 7 : 129-132. 